\title{
Athabasca University: Conversion From Traditional Distance Education To Online Courses, Programs And Services
}

\author{
Alan Davis
}

\begin{abstract}
In its 30 years of operation, Athabasca University has witnessed the full impact of the growth of online distance education. Its conversion from mixed media course production and telephone/mail tutoring to a variety of electronic information and communication technologies has been heterogeneous across disciplines and programs. Undergraduate programs in business, computing, and some social science programs have largely led the conversion, and all graduate programs have, since their inception, employed various features of online delivery. The parallel conversion of student services has been equally important to the effectiveness of these processes. The implications of this approach for the quality of offerings, support systems, costing, and the primary mandate of the University (which is to remove barriers, not create them) are discussed.
\end{abstract}

\section{Introduction}

Athabasca University is Canada's Open University and was established in 1970 by the province of Alberta. In 1999/2000 it offered courses and programs to approximately 20,000 students across Canada. As for many distance education institutions and departments, its registrations are growing much more rapidly than for campus institutions, with about $23 \%$ growth in 1999/00 to a total of about 33,000 course registrations. Full information on Athabasca University can be obtained from its comprehensive Web site [http://www.athabascau.ca].

Since half of its course registrations come from students who are "visiting" from other institutions, Athabasca University (AU) already serves a substantial national need for students to mix and match their campus programs with distance courses so they can prepare, upgrade, fit studies around work and family, and so forth. Other categories of students include those who are completing a program with the University, those who are seeking specific skills and knowledge but not a credential, those who are using the University as a cost-effective way to test their readiness for university study, and those who are taking courses for general 
Athabasca University: Conversion From Traditional Distance Education To Online Courses, Programs And Services

interest. Of the students, $85 \%$ are part-time, $75 \%$ are 25 years or older, $67 \%$ are women, and about $5 \%$ live among 67 other countries.

Over $80 \%$ of course registrations are delivered by individualised home study, and the remaining are delivered to students in paced cohorts online "e-classes" or on-site at AU learning centres or at partner institutions.

Among the features that attract so many students are AU's flexible delivery systems and the concomitant savings of opportunity and relocation costs. All of the over 525 undergraduate courses are offered by continuous enrollment, self-paced, individualised delivery, and all with some sort of online component. Graduate programs are delivered online to cohorts of students. Many student support services are also available online.

It is useful to define what is meant by the term "online" delivery in the context of AU. For the purists, online delivery occurs when (aside from assigned textbooks and some basic orientation and outlines), all instruction occurs online, such as is found in the AU Master of Business Administration (MBA) program [http://www.athabascau.ca/mba/]. In the Master of Distance Education (MDE) program [http://www.cde.athabascau.ca], however, online delivery is restricted to computer conferencing and e-mail, with more traditional distance education print packages also provided. In many undergraduate courses, teaching Web pages are available, with optional activities, online quizzes and so forth. As an example, see the Centre for Psychology offerings at [http://server.bmod. athabascau.ca/html/centre/general.htm]. For all courses, optional use of e-mail and attachments, voice mail, and Web access to services has been a major enhancement to "traditional" distance education, which relied on a print course package, fixed telephone office hours for tutors, occasional fax use, and the postal service. Thus, there is a spectrum of online enhancements at AU, many of them being optional for undergraduates, except where a computer is implicitly required, such as in Computing and Information Systems, the School of Business e-classes, and so forth.

For minimal online applications, (a largely print package with mail, e-mail, telephone and voice mail communications) AU equipped and trained all staff and tutors, established a computing helpdesk, and set clear standards for response to students. For example, see "Expect the Best" service standards at [http: //www.athabascau.ca/misc/expect/index.htm]. This level of institutional response has improved teaching and learning processes by improving the speed and quality of much of the interaction between students and the university, and gives students more control over their learning.

For more integrated systems, where content, and/or group and individual activities are delivered online, AU supports innovation through a variety of platforms and approaches to provide a wide variety of online enhancements to course and service delivery. Two main issues have arisen in connection with this type of conversion. The first issue has been to preserve (at the undergraduate level)

International Review of Research in Open and Distance Learning 
Athabasca University: Conversion From Traditional Distance Education To

Online Courses, Programs And Services

options for students who are not able to access online technologies, while exploring and anticipating ways that new technologies can enhance learning. The second issue has been to allocate resources appropriately within the university in order to support innovation and implementation of online systems, and to decide which aspects need to be centralised, and which need to be decentralised to each program or department.

In order to balance these needs, AU has endeavored to maintain a fairly open and fluid approach to the internal organisation, to allow a diversity of approaches, and to maintain a focus on the experience and needs of learners. The University has identified clear internal management performance indicators, largely focussed on the timeliness and quality of service to students, as well as policies and processes for the review of courses, programs, tutoring and services.

\section{Unique Structure, Culture and Processes at AU}

\section{Structure}

AU's mandate is unique within Canada. It is the only stand-alone distance education university, and it is mandated to reach students across Alberta and beyond. The lack of defined region is a strong advantage for AU: the provincial government, which provides the single largest source of funding, recognises the benefits (both to AU and to the province) of building the student base across Canada and beyond. The mandate also specifies a research role for AU in distance and open learning, and to provide flexibility via its transfer credit policies and practices and via collaborations.

In its mission statement, AU focuses on removing barriers for those unable to access university education, and on excellence in teaching and research. It has unicameral governance, although, to all intents and purposes, all academic matters are delegated to an Academic Council in which academic staff have a majority membership.

Approximately one third of AU's funding is provided by the Province of Alberta, with the rest from tuition and other sources. For the latest Annual Report, see [http://www.athabascau.ca/report/99]. AU has a four member executive group (President and VPs Academic, Student Services and Finance)

which deals with all management issues. Academic staff are organised into 11 academic centres, and, to a large extent, the academics themselves drive this organisation, which is intended to allow a good deal of innovation and freedom. The approximately 100 full-time faculty supervise about 400 part-time tutors and instructors.

The Student Services group has an important and parallel role in decision mak-

International Review of Research in Open and Distance Learning 
Athabasca University: Conversion From Traditional Distance Education To Online Courses, Programs And Services

ing, and provides an important balance to academic discussion with its focus on the administrative needs and experiences of students, and on the impact that a new proposal or innovation will have on the essential support services, including Library, Registry, Course Materials and Computing Help Desk.

The University has tried several ways of providing the support needed for online development and delivery, including a decentralised allocation of technical staff and resources to faculties and centres, a centralised Department of Educational Technology (with a mandate for innovation and service), and a lower-profile Educational Media Development group. No doubt further evolution of centralised and decentralised resources will occur in the future as AU tries to match changing needs with available funding and staff. A defining feature of AU is its ability to react quickly to such changes, although the constant ambiguity of structure and reporting relationships has its stresses on staff and systems.

Finally, the University has a Research and Institutional Studies unit. This combination not only provides support to academics engaged in research and the basic institutional data need by the University, it also houses the Institute for Research into Open and Distance Learning, which encompasses all the "missioncritical" research undertaken to evaluate and explore the experiences of AU's own students.

\section{Organisational Culture}

The culture at AU, certainly in the last 5 years, has been influenced by: (a) growth in numbers of students, registrations and programs; (b) the drive for quality in all student services; (c) the expanding number of partnerships with many organisations; and (d) the incorporation of new communication technologies. These developments all make for exciting, though sometimes stressful, times. The Strategic University Plan for 1996-1999 and its 2000-2003 update are fairly focussed, short documents used to determine development and operating plans for academic and administrative matters. The Strategic University Plan and Update can be found at [http://www.athabascau.ca/html/info/ sup/sup.htm] and [http://www.athabascau.ca/reports/sup99-03.htm].

Compared to many universities, AU is fairly fortunate in having a reasonably narrow mandate, and the ability to respond quickly to change. With the growth of interest in and use of distributed learning, AU is able to capitalise on its 30 years of experience in distance education. However, there are tensions between:

- growth, both within Canada and increasingly internationally, and quality;

- the need to have some centralised systems and policies, and the need for distributed systems to permit innovation; and

- the drive for more use of technology and the possible consequent exclusion

International Review of Research in Open and Distance Learning 
Athabasca University: Conversion From Traditional Distance Education To

Online Courses, Programs And Services

of those learners $\mathrm{AU}$ is mandated to serve.

An important and unique aspect of AU is the cadre of part-time remote tutors who provide, along with the academics, the teaching "front line." Many of these tutors have been with $\mathrm{AU}$ for a long time and they provide outstanding service to students. The incorporation of online communications has changed their work radically, requiring them to log in regularly, as opposed to one or two fixed telephone office hours. The transition, in consultation with the union, has been smooth.

\section{Processes}

Underlying the AU Strategic University Plan is a set of nested operational plans for each academic, service and administrative centre. These rolling, 3-year plans collectively provide a detailed and fairly coherent overview of where the University is headed.

For undergraduate course and program development an Educational Plan provides general direction for the curriculum and aspects of its delivery. Each academic centre then has its own plan that is rolled up into a detailed 3-year development cycle. This is used to project the resources that are needed for academic staff, professional technical staff, and so on. Centres are free to adapt their processes to meet curriculum and teaching needs, and have a fair amount of discretion in using savings in their delivery budgets, which are incremented quarterly to match growth in enrollments, to incorporate more online systems.

Graduate centres run on a cost recovery basis, and have autonomy and responsibility for generating registrations, and using the revenue to build their systems, faculty and so on. In accordance with University policies on human resources, finance, and so forth, their business plans are approved by the Executive Group, and are vetted by Academic and Governing Councils. The general approach, however, is to provide graduate centres with as much freedom as possible to allow them to achieve their goals of growth and quality.

\section{Societal Context within Canada}

The most direct description of the socio-economic status of Canada is to cite the United Nations Human Development Index (United Nations Development Program, 2000). Overall, Canada consistently ranks first. Thus, more than any other country in the world, Canada should have the resources and infrastructure to provide the highest quality services and programs to its citizens, wherever they live or whatever their circumstances.

International Review of Research in Open and Distance Learning 
Furthermore, distance education in Canada has a long and important history (Roth, 1986). Despite this, there have been enormous gaps and errors in the effort to extend education effectively to all parts of the country. For instance, $72 \%$ of northern Alberta communities have few or no post-secondary educational services (Alberta North, 1994). For more information on Alberta North, a consortium of northern Alberta colleges and Athabasca University, see [http: //www.abnorth.ab.ca].

For instance, in the mid 20th century, many Aboriginal students were relocated from their homes to residential schools. Low participation rates in postsecondary education in remote northern communities suggest that mistakes have been made, and opportunities have been missed. Obviously there were other agendas at work as decisions were made over the years to centralise most university education in the southern cities, and to take Aboriginal children away from their parents. However, it would be incorrect to applaud the profile that Canada has in distance education, without also recognising that its use has been limited, and that until recently it was perceived by most campus institutions as being of lesser quality at best.

Post secondary education in Canada is a provincial responsibility, and the federal government transfers tax revenues each year to the provinces accordingly. While provincial governments are able to respond more readily to local needs, the lack of a national approach to education has its drawbacks. For instance, universitytrained teachers in one province may have to requalify and recertify if they move to another. However, with the increase in distance education, provincial jurisdictions are being challenged.

The province of Alberta generally subscribes to the idea of minimal government infrastructure. Decisions made by the University, though subject to Ministry approval, have been ratified quickly, in recent years, and a good deal of support has been expressed for AU's successes. In short, the provincial government, especially compared to others in Canada, is unobtrusive, enabling and supportive. While we could always all use more operating funds, the strong economy in Alberta has led to considerable investment in all areas of education. For instance, $\$ 40$ million $(\mathrm{Cdn})$ was shared with post-secondary institutions over 4 years via a Learning Enhancement Envelope. Most of this funding initiative was used to develop online systems.

In terms of the availability of technology, the most recent surveys indicate that $42 \%$ of Canadians have access to the Internet at home or at work (Statistics Canada, 2000). AU students indicate a similar penetration and availability of technology.

Finally, AU faces increased competition for its students from campus universities that are moving online in various ways, and foreign institutions marketing their online programs in Canada. AU has responded to this increasing competition in two ways. First, it has taken steps to ensure that AU's programs 
Athabasca University: Conversion From Traditional Distance Education To

Online Courses, Programs And Services

and services, whether online or not, meet students' needs, maintain flexibility, are learner-centred, and are of the highest quality. Second, it has built alliances with other online providers provincially, nationally and internationally to ensure that, collectively, more programs are available and that marketing and delivery costs can be consolidated. See for instance the Canadian Virtual UniversityUniversite virtuelle canadienne at [http://www.cvu-uvc.ca] and the Global University Alliance at [http://www.gua.com].

\section{Institutional Demands}

As indicated earlier, AU has a fairly coherent and integrated planning approach, stemming from the Strategic University Plan. Planning in detail for 3 years is becoming rather difficult, and while AU expects to be responsive to a changing environment, there is still a tension between trying to be as concrete and clear as possible about what is to be done, and what is actually undertaken. This is manifested, especially (though not exclusively) in the academic centres. Academics, being essentially creative people, prefer to devise and explore their own approaches to anything, and resent being told how their courses and programs shall be delivered. While wishing to support this creativity, which has led to a great deal of innovation over the years, the University as a whole is concerned with the diversity of systems it has to support, whether by the number and location of servers, technical helpdesk support, training, numbers of variations of course materials that need to be developed and inventoried, and so forth.

The second tension is between innovation and consolidation/reinforcement of previous work. For those centres more actively engaged in exploring online systems, the nature of the game seems to mean that once something is shown to be working, it is time to move on. Of course it is important for AU to be ready for the next generation of technologies and applications, but it must also be concerned with accommodating growth and maintaining quality in the meantime.

There is no systematic approach to these issues. To date, having open processes for budget development, program development, and technology issues, and having to deal with a relatively small faculty and staff complement has allowed AU to balance the issues reasonably well.

The need to develop and provide online non-academic student services in parallel with the course and program developments is crucial to AU's success. Again, in an increasingly competitive environment, the quality of these services will separate AU from others who approach online learning.

For its research profile, AU supports both disciplinary research, and missioncritical research which investigates various aspects of AU's offerings, systems and services. The Institute for Research in Open and Distance Learning collects 
and organises this research, and this online journal [http://www.irrodl.org] is another manifestation of AU's commitment to learn from its own work and from others'. For some AU academics, the scope of research and scholarship for which they are responsible is thus wider and more flexible that for other universities. As is true for other open and distance universities, AU is a "laboratory" of distance and online learning, and legitimate research and development in these areas is included in any review of promotion and tenure.

\section{Critical incidents in the conversion}

Before describing some of the course and program developments in online learning, it is more important in AU's case to discuss the more general impact of the WWW and related online technologies on the University and its service to students. Like other institutions, AU has had to update its student information system to one that uses a relational database, and which will, when completed, interface with other systems, including finance, tutor payroll, course inventory, class lists, student records, and library systems. This not only will be more efficient for the University and allow it to cope with change and complexity more effectively, but it will increasingly empower students, who will (with a browser and student number) be able to access a host of information and services related their studies. This is a diverse and complex development, and Table 1 gives examples that illustrate what this emerging technology backbone means for online learners. It is likely that none of these is, in and of itself, unique, but the application to online education and the interface between them is as important as, say, intense academic debates about the merits of various learning platforms.

Table 1 (see below/end)

With regard to academic offerings, three examples are cited here to cover the range of approaches AU has seen, and which occurred roughly simultaneously over the past 5 to 6 years.

Studies in Computing and Information Systems (CIS) [http://ccism.pc . athabascau . $\mathrm{ca}$ ] have a natural fit between the interests of faculty and students. It can be assumed that, in order to study in this area, students will not only be equipped for online delivery, they will already be interested in and adept in a variety of computer skills. They will likely be keen not just to be given their courses online, but also to be actively involved in their design and development. This indeed has been the case. As the CIS courses have been developed and converted to online delivery, students provide feedback and ideas on the WWW delivery platform, provide suggestions for new freeware that can be added to the learning toolbox, and serve on a student virtual helpdesk. The CIS centre and programs therefore provide an excellent environment of development for 
Web online learning systems. Not all of the CIS developments are applicable to all other centres, of course, where academics and students may simply want a fixed, reliable and effective teaching platform.

The online Master of Business Administration [http://www.athabascau.ca/ $\mathrm{mba} /$ / offered through AU's Centre for Innovative Management (CIM) [http: //www.athabascau.calendar/00/grad9_4.html] was the first online program of its kind in North America, and is now the largest MBA program in Canada. This venture is an interesting case study in and of itself, not just in terms of online learning, but also as a stand alone business (it is fully cost recovery) and as a way in which universities can launch new innovative programs.

CIM started with a loan of about $\$ 1$ million (from unallocated university surplus funds) and a blank sheet of paper. A core of academics elected to join CIM. Lotus Notes was chosen as the groupware and learning platform, a curriculum was devised that reflected the needs of modern managers, and policies and processes were adopted that were learner-centred. Interestingly, although the program has been a huge success (there are over 1,000 active students in the program today, and it is Canada's largest MBA cohort), in attempting to explain and share the technology and principles with others, the main barrier to understanding it is not the online technology but one of academics' attitudes toward:

- teaching and learning;

- the power of collaborative learning (whether online or not); and

- the importance of excellence in "customer service" in an academic environment.

The influence of CIM has been felt throughout the university, especially by showing the importance of service to students, by reminding us that risks sometimes need to be taken, and by identifying the keys to success. All graduate programs at $\mathrm{AU}$ are delivered online to student cohorts using a variety of platforms, and the experience of CIM and the other original graduate program, the Master of Distance Education, has been invaluable to other units at AU.

A third example of a critical development at $\mathrm{AU}$ is at the other end of the scale to the previous case in terms of risk and investment, but is no less important or successful. During the same period as the development of CIM and with the leadership and support of its academics, the Centre for Psychology understood and took advantage of the power of the WWW to enhance traditional individualised distance delivery [http://server.bmod.athabascau.ca/html/centre/ general.htm]. The Centre began by allocating its annual surplus to fund a part-time programmer, and now receives annual one-time funds from the University to continue its work. The Centre has developed a comprehensive set of WWW resources that students with online access can use to obtain a variety of 
learning tools, including online quizzes and assignments, course materials, peer support, glossaries, links to AU services, hot links, and so forth. In the same period, the Centre has maintained the "print plus telephone" options for its courses, and enrollments and programs have also grown dramatically. Psychology is one of several academic centres that have steadily added WWW options over the years, and it represents the most unstructured and unanticipated type of innovation. It has shown us that, given the freedom and even a small amount of funding and support, academics with an interest and some background in online learning can achieve a great deal from their own desktops.

These examples are intended to show that innovation in online learning at AU has occurred successfully in all disciplines, has originated through both major, planned investments and through much smaller, somewhat ad hoc approaches, and using entirely different approaches to technology.

\section{Consequences}

\section{Diversity}

The diversity of approaches to incorporating online learning technologies at $\mathrm{AU}$ has had its benefits, but also created some stresses. There obviously would have been some great efficiencies had AU adopted a single learning platform. Training, technical and design support, staffing, and related costs would have been minimised, as would the demand on all concerned to cope with constant ambiguity and change.

However, the wide array of experience and developments in various approaches and platforms would not have been gained, and not to explore and develop platforms would be inconsistent with AU's mandate to be a leader in open learning. It is clear that AU's current strengths and opportunities in online learning have arisen from the relative freedom of academic centres to explore technologies, with concomitant support from the service areas.

But what of the students? What is their experience with this approach, where they may be taking several courses that have different online approaches? The evidence that we have is that this is but a minor factor in their satisfaction with AU. First of all, one can no longer simply refer to students as any sort of homogeneous cohort, given the wide variety of backgrounds, experiences with technology, and academic goals at AU. For instance, when AU surveyed students who used the undergraduate business Lotus Notes-based courses, those who were visiting for one or two courses only were less satisfied than those who were there to take a complete set of courses towards a credential. The visiting students found the installation of Lotus Notes and the ensuing learning curve to be too time consuming and cumbersome. The credential seeking students, once they 
became familiar with the system, found it to be effective. Students taking CIS courses have reported similar experiences.

$\mathrm{AU}$ has no evidence from its students that the diversity of approaches to online technologies is an impediment to their learning, nor to having a sound learning experience, no more indeed than the diversity of approaches, seating arrangements and activities they would experience in classrooms on a campus. Furthermore, students who choose online learning are already experienced with the WWW, and are perfectly able to quickly determine how to navigate any site. Lack of a uniform approach across a discipline or across the University does not appear to be a key success factor for online learning. Indeed, in recent Alberta government studies, AU students' level of satisfaction with the quality of their educational experience was seen to be far above the provincial average, which is dominated by the student responses from the large, campus based universities. For more information, see [http: //www.athabascau.ca/reports/survey99.htm].

\section{Effectiveness}

The factors that are important to the effectiveness of online systems are the same for any teaching and learning system (Chickering \& Ehrmann, 1996). For $\mathrm{AU}$, the experience in distance education has provided a wealth of experience in developing effective materials, with clearly stated objectives, well-written, edited and designed content, a team approach to development, constant peer review, commercial quality in production standards, and so on. All these attributes are carried forward to the online environment. In addition, prompted by the increasing use of online technologies for communication, and consistent with these principles, AU has developed clear standards for responsiveness to students not only on course related matters with their tutors, but also with all related student service departments. For example, see [http://www.athabascau.ca/ $\mathrm{misc} /$ expect/index.htm].

Not only has the online environment driven faster responses to student inquiries, it has also enabled more interactions among students, and a variety of either optional or required activities: simulations, case studies, projects and so forth. In a recent comparative study of MBA students at $\mathrm{AU}$ and at the University of Western Ontario, the learning experiences of students were explored in some detail. Some preliminary data on the advantages of the online environment in some of the domains indicates the following:

- AU students engage in more interaction of an explanatory nature - interaction in which they explain to each other what they think about the case study or discussion topic.

- AU students engage in more interaction of a cognitive nature - to argue 
their position on a case study, to justify their own views and to critically reflect on the positions of others.

- In a series of questions related to the impact of the communications medium (face-to-face, videoconference or online) on their ability to resolve disagreements, create common understanding, and so forth, the online interaction ranked equal or possibly better than the other two modes (P. Carr, personal communication, November, 2000).

In 1999, AU created the Research Centre, with a mandate to support disciplinary research among individual academics, and to coordinate mission-critical research at the University. Because the University's Institutional Studies function is also located in the Research Centre, there is a substantial and important capacity for AU to independently investigate its own practices. Often, this occurs within the context of program or course reviews, or in the cycle of reviews of student service areas. In other cases, special reviews of delivery platforms are undertaken. Not surprisingly, an important area of such research is the effectiveness of the online learning environments that AU is developing. A cross-university Educational Review Committee oversees these activities.

\section{Implications}

To a large extent, the overall impact of technology at AU is similar to that in any service-oriented industry. In order to meet students' expectations, to enhance learning, and to expand its student base across Canada and beyond, the University is systematically replacing its core systems (student information, finance, course materials, Library, etc.). It is also implementing a number of platforms that are designed to either enhance AU's long established and successful individualised study delivery modes, or to create new, online learning environments among student cohorts.

One key discussion that was held early on in the conversion was the impact of online conversion on accessibility. When only the minority of students had online access, such concerns were common, but since nearly $80 \%$ of students now have access to appropriate hardware and connectivity, the question now is - when will online access be mandatory for AU students? For undergraduate courses for which a computer would not normally be required, a non-online option will still be available, and a core set of materials (largely print, but sometimes with other media) will be prepared according to the policies and standards that AU has established over its 30 year history. For CIS and other computer-related courses, online access is required, as it is for graduate programs. With this policy however, there is some concern that the online conversion may be slowed or stalled by the insistence by many at AU for having only optional online activities, in an effort to preserve access for a declining percentage of students.

International Review of Research in Open and Distance Learning 
Be that as it may, the strong tradition of the University as an open institution, with its mission to remove barriers, will drive the decision for some years to come.

In terms of allocating resources for online conversion, the approach has been somewhat ad hoc, but, in retrospect, it has been effective. Since there have been a diversity of approaches to online learning rather than wholesale adoption of one platform, resources have been distributed incrementally and widely. Thus, the effectiveness of each approach can be determined before more resources are allocated. Similar approaches have occurred in other aspects of administration, be it the growth and development of the computing helpdesk, the support needed for servers, and the development of policies and standards. So far, the University has been able to build on its distance education systems, rather than having to reinvent and reengineer its systems. For new initiatives such as the graduate programs, CIS, and new e-commerce courses, a more deliberate approach to adopting online systems has been taken, with appropriate modifications to existing practice being permitted where a clear rationale is provided.

There are a number of specific implications of the diversity of conversion processes that will require ongoing discussion and adjustments at AU. In terms of quality control, a common framework for assessing the effectiveness of any platform or approach is needed in order to compare systems and to draw useful conclusions for future development. Such frameworks have been described (Eastmond, 1995) and it will be a major initiative of the aforementioned AU Research Centre to develop a coherent approach to quality control among the various online teaching and service systems.

The separation of course development from course delivery, found in the traditional, largely print-based, distance education system, is narrowing as AU adopts more online approaches and enhancements. While this convergence of development and delivery helps solve the issue of maintaining course currency, it has all sorts of implications for the University, from the very general (e.g., the allocation of resources among academic and service areas), to the specific (e.g., maintaining an accurate inventory of course materials). This convergence also impacts the scalability of the University's offerings. The model of investing heavily in a course package that can serve many enrollments, plus a scalable delivery system of tutors, is gradually becoming less applicable. In the undergraduate School of Business, the parallel offering of courses to individual students (using a core course package and optional online enhancements) as well as to cohorts of students in an integrated online environment will allow AU to look closely at whether the purported savings of development resources in the latter is sufficient to cover the increased delivery costs, and whether there are limits to growth of registrations in the cohort based online model.

For the academic staff, the last 5 years has been a time of extraordinary growth and change, and, with a few exceptions, each academic is working on some aspect 
Athabasca University: Conversion From Traditional Distance Education To

Online Courses, Programs And Services

of online conversion or course and program enhancement. Since academics have different ideas, backgrounds and levels of expertise, support staff (designers, editors, visual designers, etc.) are organised and trained to respond in a number of ways in each course team. This leads to interesting implications for human resource management. As the various learning platforms and their associated human resource needs evolve, there is a continual emergence of new position types, and levels within these types. Each learning system requires a unique blend of technical, design and pedagogical expertise, and once each position is established, the needs evolve rather quickly. In terms of traditional human resource management of recruitment, classification, reclassification, and salary adjustments, this rather rapid flux in the supply of, demand for, and shifting complexities within technical and design staff results in increased workload for the human resource unit. This situation may even suggest a new approach to establishing such positions, with new systems of classification and remuneration that reflect the very dynamic working environment.

\section{Conclusions}

AU's approach to the conversion of its courses and programs to online has been to (a) encourage a diversity of approaches, (b) balance the need for centralised versus distributed technical and design resources, (c) focus on the concomitant conversion of all student services, (d) establish student service standards, and (e) conduct research focused on effectiveness of all these developments. AU recognises that it will need to adapt its approaches continuously in order to increase the quality of its offerings and services, and it will need to partner with other institutions to expand its offerings and to increase access for students in Alberta, throughout Canada and internationally. 
Athabasca University: Conversion From Traditional Distance Education To

Online Courses, Programs And Services

\section{References}

Alberta North (1994). Alberta-North - Design and development document, Athabasca, AB: Athabasca University, [internal document].

Chickering, A. \& Ehrmann, S.C. (1996). Implementing the seven principles: Technology as lever. Retrieved December 21, 2000: [http://www.aahe. org/Bulletin/SevenPrinciples.htm].

Eastmond, D. V. (1995). Alone but together: Adult distance study through computer conferencing. New York: Hampton Press.

Roth, J.P. (1986). An historical perspective. In I. Mugridge and D. Kaufman (Eds.), Distance Education in Canada (pp. 4-24). London: Croom Helm.

Statistics Canada (2000, May). Household Internet use. Retrieved December 21, 2000: [http://www.statcan.ca:80/Daily/English/000519/d000519b.htm].

United Nations Development Program (2000). Human development report. Retrieved December 12, 2000: [http://www.undp.org/hdr2000/english/ HDR2000.html].

Citation Format

Davis, Alan (January 2001) Athabasca University: Conversion From Traditional Distance Education To Online Courses, Programs And Services. International Review of Research in Open and Distance Learning: 1, 2. http://www.icaap.org/iuicode?149.1.2.9 
Athabasca University: Conversion From Traditional Distance Education To Online Courses, Programs And Services

Table 1: Impact on learners of some online initiatives at Athabasca University

\begin{tabular}{|c|c|}
\hline $\begin{array}{c}\text { Online } \\
\text { Initiative }\end{array}$ & Description and Impact \\
\hline AU Web site & $\begin{array}{l}\text { A comprehensive Web site, an easily accessible and navigable } \\
\text { information source for potential and current students, is } \\
\text { fundamental to all organisations. For an institution such as AU, } \\
\text { it is critical. One measure of its impact is that AU's site receives } \\
\text { about } 1 \text { million hits a week, } 15 \% \text { of which can be ascribed to } \\
\text { internal use. }\end{array}$ \\
\hline $\begin{array}{l}\text { Information } \\
\text { Centre and } \\
\text { Intranet }\end{array}$ & $\begin{array}{l}\text { The Information Centre backs up AU's Internet site. Attendants } \\
\text { have access to a wealth of information, provide students with } \\
\text { better response to telephone inquiries, and, as far as possible, } \\
\text { deal with each inquiry without further referral. This is enabled } \\
\text { by a comprehensive Intranet and read-only access to other } \\
\text { databases. }\end{array}$ \\
\hline PLA online & $\begin{array}{l}\text { Together with Laurentian and Lakehead Universities, AU has } \\
\text { developed an online prior learning assessment (PLA) process. } \\
\text { Students can easily access the portfolio format and guidelines as } \\
\text { well as develop and submit portfolios for assessment at } \\
\text { [http://www athabascau.ca/html/depts/lmacc/general.htm]. }\end{array}$ \\
\hline Library & $\begin{array}{l}\text { AU's Library [http://www athabascau.calibrary/] has an } \\
\text { electronic gateway. Students can access a range of library } \\
\text { services and a constantly increasing number of databases, many } \\
\text { with full text. Online library service goes a long way to } \\
\text { eliminating the traditional problems and perceptions related to } \\
\text { library support for distance leamers. }\end{array}$ \\
\hline $\begin{array}{l}\text { Collaborations } \\
\text { page }\end{array}$ & $\begin{array}{l}\text { Articulation agreements with colleges and professions are } \\
\text { accessible online. Students can see for themselves what options } \\
\text { they have in transferring to AU [http:/www.athabascalu.ca/cgi- } \\
\text { bin/credit transfer.pl]. }\end{array}$ \\
\hline $\begin{array}{l}\text { Virtual } \\
\text { Helpdesk }\end{array}$ & $\begin{array}{l}\text { The Virtual Helpdesk } \\
\text { [http//ccism.pc.athabascau.ca/htm } 1 \text { students/stupage/whd.htm], } \\
\text { developed by the Centre for Computing and Information } \\
\text { Systems, is staffed by students to help other students. It is key to } \\
\text { building a community of interest even among self-paced home } \\
\text { study students not part of a course or program cohort. }\end{array}$ \\
\hline
\end{tabular}

International Review of Research in Open and Distance Learning 